Renata Scheeren Brum ${ }^{1 *}$ (1) Camila Rodrigues de-Souza ${ }^{1}$ Daltro Enéas Ritter ${ }^{1}$ Roberto Rocha ${ }^{1}$ Cláudia Ângela Maziero Volpato ${ }^{1}$ César Augusto Magalhães Benfatti ${ }^{1}$
${ }^{1}$ Universidade Federal de Santa Catarina, Odontologia - Florianópolis - Santa Catarina - Brasil.

Correspondence to: Renata Scheeren Brum.

E-mail: renatasbrum@live.com

Article received on November 3, 2020. Article accepted on June 17, 2021.

DOI: 10.5935/2525-5711.20210009

\section{Orthodontic-Prosthetic Rehabilitation of Congenital Alveolar Cleft: A case report from infancy to adulthood}

\begin{abstract}
:
Introduction: Cleft lip palate (CLP) treatment is challenging and requires multidisciplinary treatment during patient's whole life. Aim: To present a case report of a life-time CLP rehabilitation that anatomic features required advanced rehabilitation modalities. Design: A 9-year-old patient was diagnosed as unilateral right CLP. Agenesia and poor prognosis of lateral and central right incisor respectively added complexity to multidisciplinary treatment planning. Results: Orthodontic and surgical procedures performed during infancy and adolescence resulted on satisfactory dental alignment. Anatomical limitations required installation of a hybrid dentogingival implant-supported prosthesis at adulthood. After 3 years of follow-up, implants were osseointegrated and peri-implant tissues were stable, with favorable esthetic and functional outcomes. Conclusions: This challenging case of cleft lip palate, on which tooth with poor prognosis and agenesia were identified, required a multidisciplinary treatment during infancy and adolescence in order to provide adequate conditions for implant placement at adulthood. Implant therapy in complex cases of CLP patients requires advanced treatment modalities, that may include guided bone regeneration, periodontal reconstruction and dentogingival prosthesis.
\end{abstract}

Keywords: Alveolar Bone Grafting; Cleft Palate; Dental Implants; Orthodontics; Case Report 


\section{BACKGROUND}

Cleft lip and/or palate are the most common congenital malformation and its incidence is estimated in $1 \mathrm{cleft}$ child for 560 live births. ${ }^{1}$ Labiomaxillary clefts results from the deficiency or the lack of fusion among maxillary and nasal process during the 36/37th day of intrauterine life (IUL). ${ }^{2}$ Genetic and environmental factors are involved in its etiology. Specifically, cleft lip and palate in its unilateral form involves upper lip, maxillary and alveolar bone (at the region among lateral incisor and canine), hard and soft palate, which creates oro-nasal communication. ${ }^{2}$

Individuals with CLP suffers from problems with feeding, speaking, hearing and social integration. ${ }^{3}$ Multi-disciplinary treatment is required: it is initiated by the pediatrician in the immediate neonatal period and goes along the whole life of the patients, encompassing maxillofacial surgery, orthodontics, speech therapy and psychotherapy, among others. ${ }^{4}$ It is desired that early diagnosis and interventions can offer CLP patients natural teeth maintenance and proper occlusal conditions. ${ }^{5}$ However, in more severe cases, anatomic aspects can difficult this ideal situation and, when a cleft area is stricken by tooth loss, implant-support rehabilitation may be required. ${ }^{6,7}$

A recent systematic review has evaluated 483 implants installed at grafted areas from CLP patients, with a survival rate of $93 \%$ after a mean follow-up period of 60.5 months. Despite the high survival rates, there are substantial difficulties associated to the implant therapy in CLP patients, that can be listed as follows: interest area has generally been treated at least twice before implant placement implying in tissue scars; implants are usually inserted at augmented bone; necessity of additional bony augmentation during implant placement; involvement of esthetic zone.,

Considering this, it is important to highlight the importance of multidisciplinary treatment on the CL/P life-time oral rehabilitation.

\section{CASE REPORT}

\section{Diagnosis}

Patient seek for dental treatment, in 1999, when she was 9 years old. Clinic examination enabled the diagnosis of unilateral right cleft lip palate and maxillary atresia. Her medical historic included surgery of cheiloplasty by the age of 4 months old and palatoplasty at 18 months old. Radiographic examination exposed agenesia of the following tooth: second right and left premolars, as well as of right lateral incisor (Fig.1 A,B). Right central incisor presented a narrow dilacerated root with accentuated gyroversion, affected by bone support

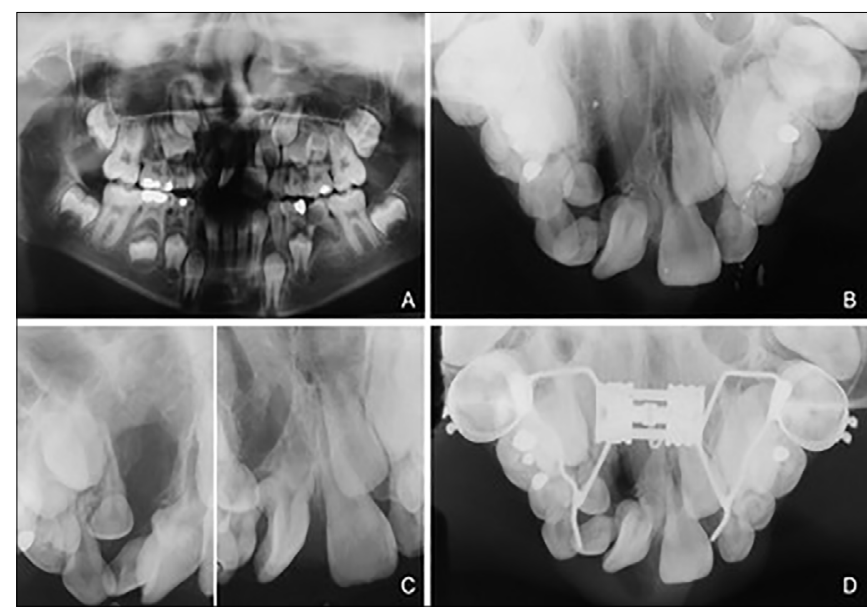

Figure 1. Initial radiographic documents at 1999 (9 years-old): A) Panoramic radiography; B) Occlusal radiography; C) Periapical radiography of right lateral and central incisors region; D) Occlusal radiography after installment of maxillary expander.

deficiency and, therefore, it was settled as a tooth with poor prognosis (Fig.1 C). Diagnosis of facial asymmetry, anterior crossbite, overjet of -3 and overbite of $-10 \%$ was settled. She was classified as Angle class I first molar relationship and Facial Class III pattern. No additional medical conditions were reported.

\section{Treatment objectives}

Main treatment objectives were improvement of patient well-being. This comprised good oral and systemic health, as well as proper social integration. Therefore, special focus was directed for obtainment of excellent speech and nutrition function, accompanied by achievement of facial symmetry (ideal overjet, overbite and proper intercuspation) and improvement of smile harmony.

\section{Treatment alternatives}

Alternative treatment modalities would be encouraged if maxillary expansion and forward traction were not effective. This could occur in case of bad cooperation or excessive mandibular growth surpassing maxillary advancement. In this situation, maxillary surgical expansion and Le Fort I advancement could be performed. In which concerns prosthetic rehabilitation, at anterior maxillary teeth absence area, in case of bone graft failure, which would not allow implant osseointegration, an alternative could be a fixed or bonded prosthesis to surrounding teeth.

\section{Treatment progress}

Patient treatment is summarized at Graphical Abstract. 


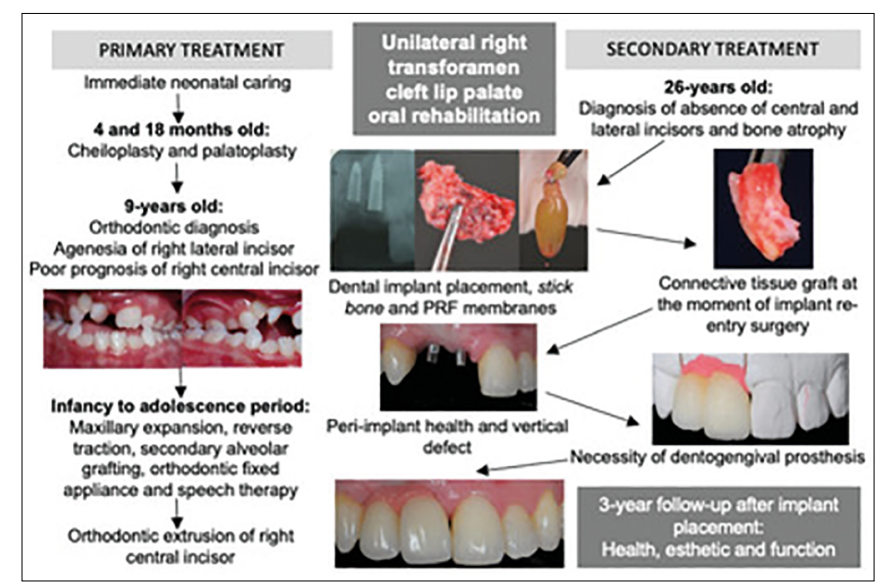

Graphical abstract: Summary of treatment sequence.

\section{Primary treatment phase}

Treatment planning encompassed maxillary expansion (Fig.1 D, Fig.2 A,B) that was performed by the age 9 until 11 years old. Reverse traction that was performed by the the end of this period, employing the expander as anchor. Secondary alveolar grafting (donor region: iliac bone) was performed by the time that the canine adjacent to the cleft region had its rhizogenesis between half and three quarters completed, as recommended by Bergland et al. $(1986)^{10}$. This occurred when patient was 12 years old. 120 days after surgery, fixed appliance was introduced for aligning, levelling and obtaining correct occlusion (Fig.2 C,D). Moreover, the space referent to the right second molar was planned to be closed through mesial movement of right superior molars. The maxillary right central incisor was extruded

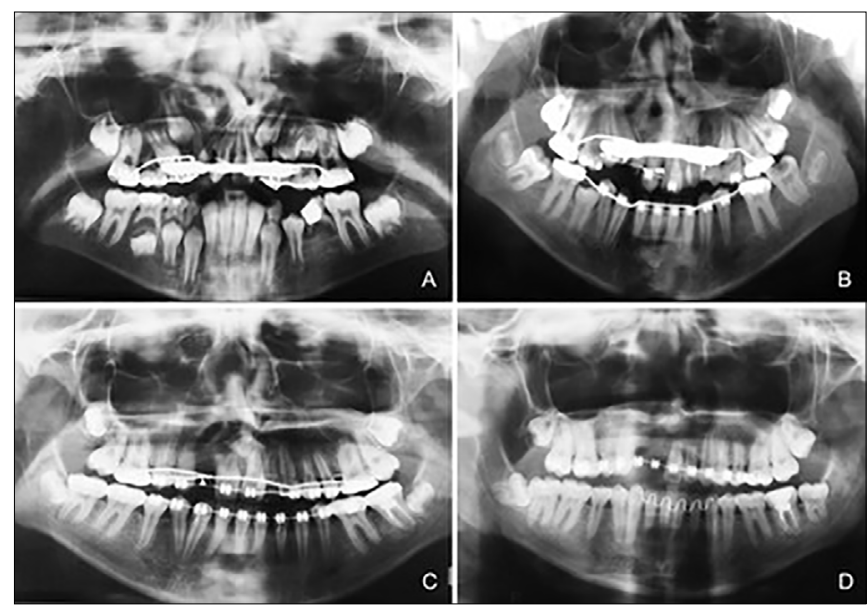

Figure 2. Panoramic radiographies of infancy to adolescence period: A) 2001 (10 years-old, maxillary expansion, mixed dentition); B) 2003 (12 years-old, maxillary expansion, end of mixed dentition, orthodontic fixed appliance at lower jaw); C) 2009 (18 years-old, orthodontic fixed appliance, extrusion of right upper central incisor ongoing; absence of lateral incisor); 2012 (21 yearsold orthodontic fixed appliance at upper jaw, absence of right upper incisors). till extraction to create bone for future implant substitution (Fig.2 C,D). Therefore, adequate space to install a dental implant at the lateral incisor position and central incisor was obtained. Through the fixed appliance treatment phase, Class III elastics were used. Patient used the fixed applied until she was 22 years old.

Orthodontic treatment provided ideal overjet, overbite and proper intercuspation. Excellent speech function was achieved. A hint of hypernasality was maintained.

\section{Secondary treatment phase}

Patient was referred for dental implant placement and prosthetic rehabilitation of right central and lateral incisors when she was 26 years old (Fig.3 A,B). Cone beam computerized tomography (CBCT) revealed bone atrophy, indicating that bone grafting was necessary (Fig.3 C,D). Two dental implants (Morse taper, $3.3 \times 8$ $\mathrm{mm}$ and $3.3 \times 11 \mathrm{~mm}$, FGM, Joinville, Santa Catarina, Brazil) were installed concomitantly to a graft of stick bone, that is, extracellular matrix from platelet rich fibrin (PRF) mixtured to xenogeneic particulate bone (Criteria, São Paulo, São Paulo, Brazil) (Fig.4 A,B). Membranes of PRF were used to cover the graft (Fig4. C). Initial torque of central and lateral incisors were $60 \mathrm{~N}$ and $10 \mathrm{~N}$ respectively. A CBCT (Fig.4 D) and a periapical radiography were performed immediately after surgery. Implants were submerged for a period of 6 months. When the re-entry procedure was performed concomitantly to connective tissue grafting (Fig.5 A,B), PEEK healing abutments (FGM) were installed (Fig.5 B). Local anesthesia and pre and post operatory medication were administered properly. After 3 months of the re-entry procedure, trunnion abutments $(\mathrm{FGM})$ were installed
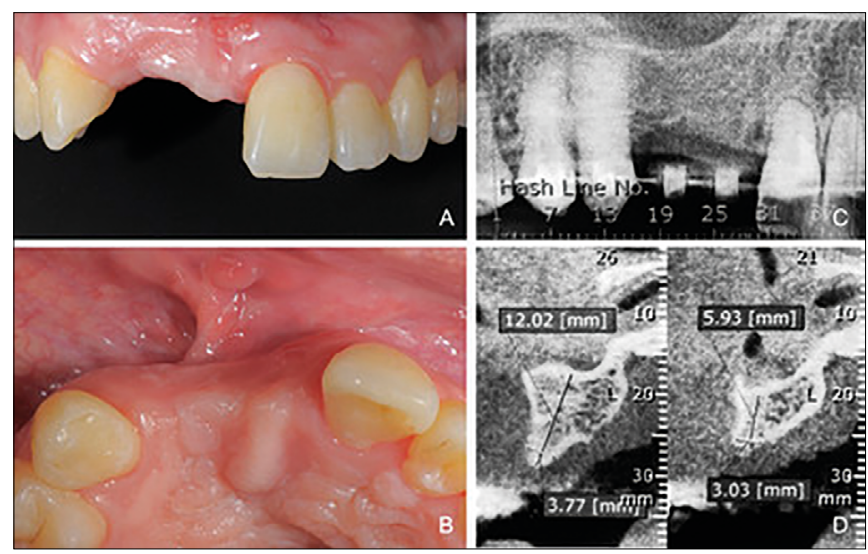

Figure 3. Images of beginning of adult treatment period at 2016 (26 years-old) A) Intra-oral frontal view; B) Intra-oral occlusal view; C) CBCT reference image D) Transversal section of $\mathrm{CBCT}$ indicating bone atrophy. 

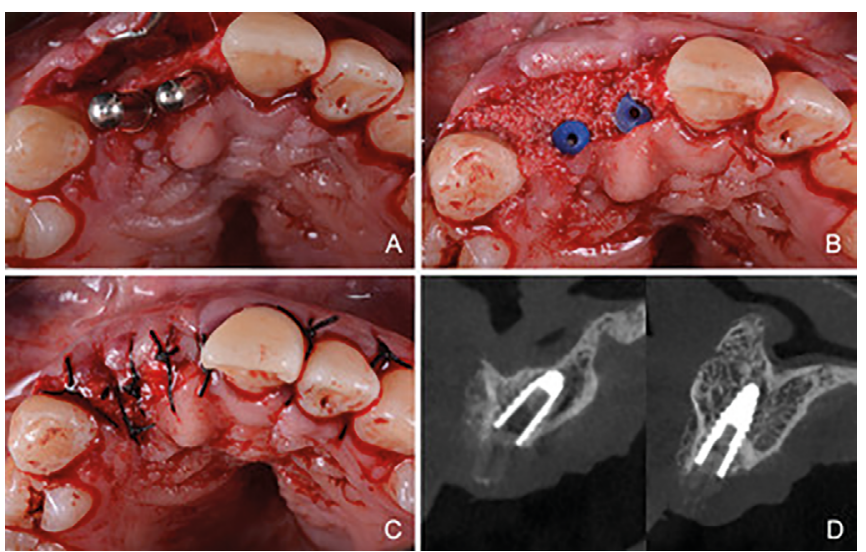

Figure 4. Trans and immediate post-surgical images: A) Check of implant adequate position; B) Bone graft positioned at buccal site; C) PRF membranes positioned at buccal region; D) CBCT transversal section.
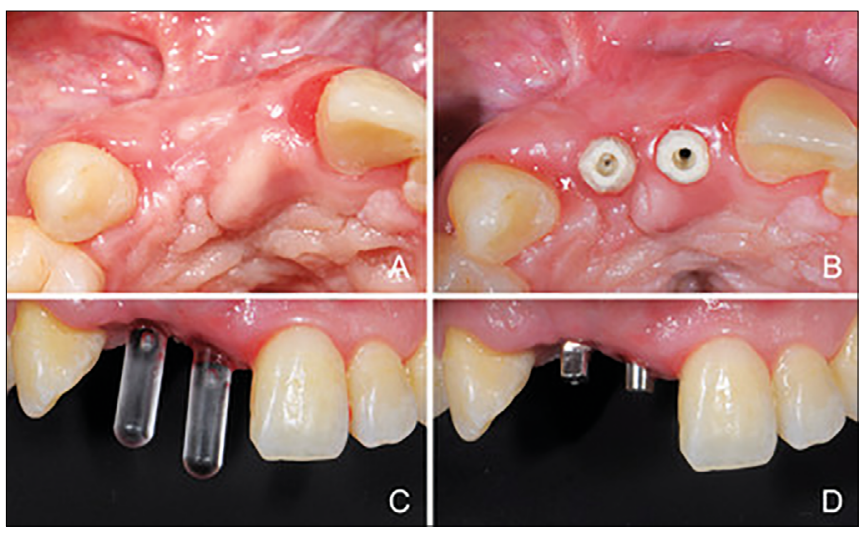

Figure 5. A) 6 months post-surgery occlusal view; B) PEEK healing abutment after re-entry surgery accompanied by connective tissue graft; C) Angulation referrers for abutment installment; D) Trunnion abutments installed.

and activated (Fig.5 C,D). Impression was performed with adittion silicone (Express XT kit, 3M, Maplewood, Minnesota, United States). A provisional implant supported prosthesis was manufactured. An hybrid linked tooth-gingiva cemented ceramic prosthesis was delivered (Fig.6 A,B,D) and another CBCT was performed (Fig.6 C). Follow-up appointments were performed regularly after prosthetic delivery.

\section{Treatment results}

Patient was satisfied with esthetic and function and was well social-integrated. CLP primary and secondary closure accompanied by speech therapy and orthodontic treatment of facial deficiencies were efficient. However, considering the lateral agenesia and the poor prognosis of the central incisor, implant installation was required. Orthodontic treatment provided adequate conditions for implant-supported rehabilitation. However, despite the fact that guided bone regeneration was performed
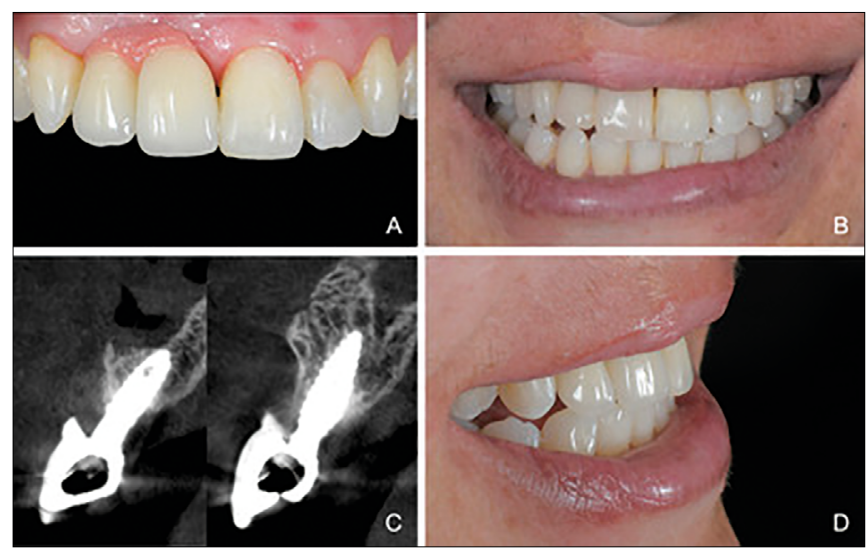

Figure 6. Images of end of adult treatment period: A) Intra-oral frontal view; B) Extra-oral frontal view; C) $\mathrm{CBCT}$ transversal section; D) Extra-oral right lateral view.

concomitantly to implant installation, the vertical bone defect required the manufacture of a dentogingival prosthesis. After 3 years of follow-up, implants were well osseointegrated and crestal bone, as well as buccal grafted bone levels were maintained. Soft tissue stability was reached and oral health was preserved. Patient's low smile line was crucial for the favorable esthetic results obtained through dentogingival prosthesis.

\section{DISCUSSION}

When dealing with oral rehabilitation of CLP patients, the high level of complexity must be treated by the multidisciplinary team through careful planning, precise techniques and close monitoring. Ideally, natural tooth should be preserved and dental implants should not be necessary for CLP treatment ${ }^{11}$.However, when challenging anatomical conditions are found, such as tooth agenesia or compromised tooth, the orthodontic treatment planning that starts at childhood must create adequate conditions for future implant placement at adulthood. At the present case, orthodontic treatment provided favorable overjet, overbite, as well as adequate posterior occlusion. A very satisfactory profile and smile line associated to high standards of oral health were also obtained. Adequate space was created for implantsupported rehabilitation of anterior maxillary region.

In which concerns bone grafts, this patient went through a conventional iliac graft for secondary closure at the Primary Treatment Phase. This procedure is very important because it enables permanent teeth eruption, dental maxillary dental arch stabilization, nasal fistulae closure, orthodontic treatment and, when required, implant placement. ${ }^{4}$ PRF, which was used concomitantly to 
implant installation mixtured to xenogeneic particulate bone at the present study at the Secondary Treatment Phase, is a suitable candidate to substitute and/or to be combined with more conventional bone grafts in maxillofacial surgery. ${ }^{12}$ PRF posses biologically active compounds that enhance tissue repair mechanisms of chemotaxis, cell proliferation, angiogenesis, osteogenesis and remodeling. ${ }^{12}$ A study from Al-Ahmady et al. $(2018)^{13}$ has examined the use of autologous bone marrow mononuclear cells, combined with PRF and nanohydroxyapatite for alveolar cleft repair, compared to the standard technique of iliac crest bone, through a 12 months follow-up, via clinical and radiographic assessments. The modernizer group has exhibited less donor site complications, improved soft tissue healing, less postoperative pain, associated to better rates of alveolar bone union. ${ }^{13}$

At the moment of implant placement and re-entry surgery guided bone regeneration and connective tissue were respectively performed in order to achieve more favorable results. Interestingly, a successful 10-year follow-up case report from Hengjeerajaras et al (2019) ${ }^{14}$ of CLP patient who had undergone through lip, palate and orthognatic surgery accompanied by orthodontic treatment had also employed guided bone regeneration to achieve adequate outcomes. The technique for anterior tooth replacement with an implant-supported rehabilitation employed bone decortications, employment of collagen membrane and xenogenous bone, followed by 6 months of healing before implant placement. After prosthetic load, connective tissue graft was employed, which resulted in a healthy esthetic and osseointegrated implant rehabilitation. ${ }^{14}$

The stick bone employed at the secondary treatment phase provided adequate horizontal bone gain for implant placement. However, the bone height defect was not compensated because it requires advanced treatment guided bone regeneration procedures, increasing complications rates ${ }^{15}$. Therefore, the dentogingival prosthesis was unavoidable. A study has evaluated esthetic aspects of 39 unilateral CLP patients that went through secondary alveolar cleft closure and received single implants placed at lateral incisors after orthodontic treatment. ${ }^{16}$ Among the most common esthetic complications, elongated teeth and absence of papillae were reported. ${ }^{16}$ In the present case, the dentogingival prosthesis was capable of avoiding these common issues and, associated to patient's low smile, adequate esthetic results were achieved.

\section{CONCLUSIONS}

The present case report exhibited an exception protocol of cleft lip palate treatment, on which severe anatomic conditions required the creation of favorable conditions during infancy and adolescence through orthodontic treatment for dental implant rehabilitation at adulthood. In order to achieve proper functional and esthetic outcomes the following steps were required: immediate neonatal caring; primary treatment (interceptive or thodontic treatment, speech therapy and secondary alveolar closure through iliac graft surgery at adolescence); secondary treatment (guided bone regeneration, dental implants, connective tissue graft and dentogingival prosthesis).

\section{REFERENCES}

1. Pigott RW. Organisation of cleft lip and palate services - results of a questionnaire. Br J Plast Surg. 1992 Jul;45(5):385-7.

2. Farronato G, Cannalire P, Martinelli G, Tubertini I, Giannini L, Galbiati G, et al. Cleft lip and/or palate: review. Minerva Stomatol. 2014;63(4):111-26.

3. Montes ABM, Oliveira TM, Gavião MBD, Barbosa TS. Orofacial functions and quality of life in children with unilateral cleft lip and palate. Braz Oral Res. 2019;33:e061.

4. Nadon F, Chaput B, Périssé J, Bérail A, Lauwers F, Lopez R. Interest of mineralized plasmatic matrix in secondary autogenous bone graft for the treatment of alveolar clefts. J Craniofac Surg. 2015 Oct;26(7):2148-51.

5. Tereza GPG, Santos MAC, Winckler VPSV, Almeida ALPF, Dalben GS. The maxillary lateral incisor in the rehabilitation of cleft lip and palate. J Appl Oral Sci. 2018;26:e20170125.

6. Wood LW, Oesterle LJ. A case report of a complete unilateral cleft of the lip and the palate from birth to 15 years. Am J Orthod Dentofacial Orthop. 1994;105(1):1-9.

7. Pucciarelli MGR, Lopes ACO, Lopes JFS, Soares S. Implant placement for patients with cleft lip and palate: a clinical report and guidelines for treatment. J Prosthet Dent. 2019 Jan;121(1):9-12.

8. Sales PHH, Oliveira-Neto OB, Torres TS, Lima FJC. Effectiveness of dental implants placed in bone graft area of cleft Patients. Int J Oral Maxillofac Surg. 2019 Aug;48(8):1109-14.

9. Wermker K, Jung S, Joos U, Kleinheinz J. Dental implants in cleft lip, alveolus, and palate patients: a systematic review. Int J Oral Maxillofac Implants. 2014 Mar/Apr;29(2):384-90.

10. Bergland O, Semb G, Abyholm FE. Elimination of the residual alveolar cleft by secondary bone grafting and subsequent orthodontic treatment. Cleft Palate J. 1986 Jul;23(3): 175-205.

11. Rocha R, Ritter DE, Locks A, Paula LK, Santa RM. Ideal treatment protocol for cleft lip and palate patient from mixed to permanent dentition. Am J Orthod Dentofacial Orthop. 2012 Apr;141(4 Suppl 1):S140-8.

12. González-Sánchez JG, Jiménez-Barragán K. Closure of recurrent cleft palate fistulas with plasma rich in growth factors. Acta Otorrinolaringol Esp. 2011 Nov/Dec;62(6):448-53. 
13. Al-Ahmady HH, Elazeem AFA, Ahmed NEB, Shawkat WM, Elmasry M, Abdelrahman MA, et al. Combining autologous bone marrow mononuclear cells seeded on collagen sponge with Nano Hydroxyapatite, and platelet-rich fibrin: reporting a novel strategy for alveolar cleft bone regeneration. J Craniomaxillofac Surg. 2018 Sep;46(9):1593-600.

14. Hengjeerajaras P, Froum SJ, Adawi HAA, Yu P, Cho SC. Anterior tooth replacement with an implant in a grafted alveolar cleft site: case report with a 10-year follow-up. Int J Periodontics Restorative Dent. 2019 Jul/Aug;39(4):511-5.
15. Troeltzsch M, Troeltzsch M, Kauffmann P, Gruber R, Brockmeyer $\mathrm{P}$, Moser N, et al. Clinical efficacy of grafting materials in alveolar ridge augmentation: a systematic review. J Craniomaxillofac Surg. 2016 Oct;44(10):1618-29.

16. Fiamengui Filho JF, Almeida ALP. Aesthetic analysis of an implant-supported denture at the cleft area. Cleft Palate Craniofac J. 2013;50:597-602. 